\title{
CONSTRUCTING AN INSTRUMENT FOR ASSESSING THE INTERNALIZATION AND ACTUALIZATION OF CULTURAL VALUES TOWARD ENGLISH FOR FOREIGN LANGUAGE LEARNERS
}

(iD) Wiwiek Afifah ${ }^{1+}$
(iD) Lucia W. Ningsih
(D) Nadhim Obaid
Hussein
Asma Aisya $^{3}$

(1)

Article History

Received: 13 October 2021 Revised: 10 January 2022 Accepted: 26 January 2022 Published: 16 February 2022

\section{Keywords}

Culture

Internalization

Actualization

Assessment

Instrument

Language learning.

\author{
'Ahmad Dahlan University, Yogyakarta, Indonesia. \\ 'Email:wiwiek.afifah@enlitera.uad.ac.id \\ ${ }^{2,4}$ Research Center for Educational and Cultural Policy, Research and \\ Development, Agency, Republic of Indonesia. \\ ${ }^{2}$ Email: luciahw@yahoo.com \\ ${ }^{4}$ Email: asmaisha.87@gmail.com \\ ${ }^{s}$ Sultan Idris Education University, Kuala Lumpur, Malaysia. \\ ${ }^{s}$ Email:nadhimiraqi@yahoo.com
}

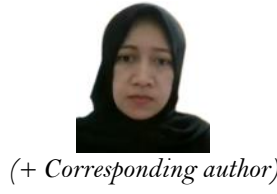

ABSTRACT

This study is aimed at developing an instrument to assess learners' internalization and actualization of cultural values through English for foreign language learning. The five phases of instructional design proposed by Cennamo and Kalk (2019) guided the research and development. The five phases of instructional design include (1) defining key terms and exploring the need to develop an instrument from a practical perspective while taking into account any theoretical gaps; (2) creating the instrument grid design and table of specifications for the design; (3) developing and modeling the instrument; (4) refining the instrument using input from forum group discussions and expostulating with expert judgments; and (5) presenting the product and testing it to the learners. The research consisted of a questionnaire, observation, and interview guide. The technique used to analyze the data was an exploratory factor analysis (EFA) with the factor loading determined by the number of samples in this research. We used the Kaiser-Meyer-Olkin (KMO) test to measure data sufficiency with levels greater than $0,05(\mathrm{KMO}>0,05)$. After analyzing the data, the results revealed 0,587 with the significance of 0,000 showing that, for assessing internalization and actualization of cultural values, there were 25 items with seven factors: deserving the value of achievement, self-confidence, creativity, respect, discipline, nationalism, and tolerance.

Contribution/Originality: This study contributes to existing literature regarding cultural learning and English language teaching. The integration of these two disciplines can be used to design instruments that map the level of a student's cultural value understanding. This study also contributes to the development of macro skills in language teaching language.

\section{INTRODUCTION}

Regarding foreign language learning, there are insufficient instruments available to assess a learner's understanding level of internalization and actualization toward culture-positive values (Berlin, 1992; Díaz-Cabrera, Hernández-Fernaud, \& Isla-Díaz, 2007; Kiss \& Nikolov, 2005). Conversely, in this digital revolution, we need 
positive values to control ourselves interacting with others around the globe. Some previous studies, such as from Staub (1979); Park and Peterson (2006); Martinez and Garcia (2008); Vauclair (2009), reported that the level of morality of today's teenagers ought to be apprehensive. It is because morality has strong power to maintain the stability of the nation. Therefore, realizing the current problem of teenagers' moralities, education should be more proactive in helping teenagers to overcome these problems. There are many studies on culture, morality, and developing instruments as they relate to issues of positive cultural values, for example, Jensen (2015); Harpham (2017); Kurth and Narvaez (2018); Staines, Formosa, and Ryan (2019) who intensively investigate the same field. However, an instrument for assessing and observing learners at different grade levels, for example, foreign language learners in junior high schools, are still scarce. Meanwhile, several studies have proven that through learning language, moralities or positive values can be inculcated (Khan, Waheed, Chengwen, Butt, \& Ahmad, 2018; MacIntyre \& Mercer, 2014; Piasecka, 2016; Talamini, Grassi, Toffalini, Santoni, \& Carretti, 2018; Zakarneh, Alsalhi, Talab, Mansour, \& Mahmoud, 2021). In addition, the integration of cultural values into language learning is great in quantity (Gabryś-Barker, 2016; Gay, 2010; Gregersen, 2016). This fact proves that there are positive responses from language teachers and demonstrates that they desire to bring good values to their teaching practices. Unfortunately, teachers who have taught languages and integrated positive cultural values do not implement a standard evaluation on monitoring and observing the learners' attainment. Thus, the evaluation of the students' learning outcomes has not been standardized yet. Therefore, the objective of this paper aims at developing an instrument to assess language learners' internalization and actualization toward positive cultural values. The output of the research is to give a contribution to English language teachers who will teach and integrate language and positive cultural values in the classroom.

\section{THEORETICAL FRAMEWORK}

\subsection{The Concept Culture}

Inspired by Kroeber and Kluckhohn (1952), Chaer and Agustina (2010) collected and categorized six definitions of culture in their research. The definitions are as follows. The first definition provides a descriptive definition emphasizing that culture that has six elements. The second is a historical definition that focuses on how culture receives social acceptance from generation to generation. The third is a normative definition analyzing culture based on the norms and ways of life. The fourth is a psychological definition that encompasses the role of culture in guiding people as a member of society. In this context, culture plays a role in directing people in adjusting or adapting to their surroundings. The fifth is a structural definition that stresses culture as a systemic, well-regulated pattern. The sixth is a genetic definition emphasizing the formation of social standards as humankind's creation. The entire definition can be interpreted to mean that culture encompasses all human activities include the consequences of human action.

There are a wide variety of cultural definitions. Kumaravadivelu (2003) and Saifer, Edwards, Ellis, Ko, and Stuczynski (2012) define culture are a complicated concept as it does not lend itself to a single definition or a simple description. Culture recalls different images of different people. In its broadest sense, it includes a wide variety of constructs such as mental habits, personal prejudices, moral values, social customs, artistic achievements, and aesthetic preferences of societies. A way of life, especially as it relates to the socially transmitted habits, customs, traditions, and beliefs that characterize a particular group of people at a particular time. It includes the behaviors actions, practices, attitudes, norms, values, communication styles, language, etiquette, spirituality, concepts of health, and healing, beliefs, and institutions of a racial, ethnic, religious, or social group. From that definition, culture is the lens through which we look at the world. Furthermore, it is the context within which people operate and make sense of the world. Those earlier definitions refer to culture as the structure of many aspects. Kumaravadevelu's rationale can be briefly broken down and understood to mean that culture encompasses mental habits, prejudice, moral values, social custom artistic achieving, and aesthetic preference. These concepts reflect 
human behavior, beliefs, and the everyday life of an individual or a group of individuals within a cultural community. With the definition from Saifer et al. (2012), this definition can be understood to mean that culture is broad since it includes a variety of aspects of people's lives.

Overall, based on those definitions, culture appertains to interrelated components. Each component implies certain values in which society adopts and uses as a way of life in their social system. Therefore, since culture covers values and norms, people must keep, preserve, and inculcate them for the next generation. In this context, education is one of the systems most appropriate for transferring values to students. In a broad sense, culture can be understood as a meaningful system that can be taught systematically in education. In the end, culture will be dynamic when societies are actively keeping and maintaining them. The effort to introduce a culture to a formal institution will then support its existence. As students learn value from culture, these lessons can be transmitted from time to time and from one generation to the next. In that way, culture gains its function as a guide by the people for interaction and adaptation with their surroundings. Through his book, Kebudayaan, Mentalitas dan Pembangunan, Koentjaraningrat (1997) explains the concept of culture as comprised of activities humans interact in throughout their life. He points out that the concept of culture can be understood in a broader sense because culture reflects the human mind, its creation, and artwork. However, it is not rooted in instinct and, thus, requires a learning process.

\section{METHOD}

To answer the research questions, we implemented educational research and development. The model that guided us in developing the instrument was the model proposed by Cennamo and Kalk (2019). The five phases of instructional design include (1) defining key terms and exploring the need to develop an instrument from a practical perspective while considering any theoretical gaps; (2) creating the instrument grid design and table of specifications for the design; (3) developing and modeling the instrument; (4) refining the instrument using input from forum group discussions and expostulating with expert judgments; and (5) presenting the product and testing it to the learners. The subject of the research was a group of students at a junior high school in Yogyakarta, Indonesia. The sample selection of the research came from four schools from four districts. There were 154 learners involved in the research. They were chosen from four schools, either state or private schools, junior high schools in Yogyakarta. The technique used to collect the data in this research were questionnaires. They were distributed to students and expert judgments.

The questionnaires were used to evaluate the students' level of internalization and actualization toward cultural values. To construct the instrument, we referred to the table of specifications using the Likert scale type. The technique used to analyze the data was factor analysis through the exploratory factor analysis (EFA). The number of samples in this research determined the factor loading within the EFA. The Kaiser-Meyer-Olkin (KMO) test was used to consider the sufficiency of the data with levels greater than 0,05 (KMO>0,05).

\section{FINDINGS AND DISCUSSION}

In developing the instrument to assess students' positive cultural values through actualization and internalization, there were five steps taken by the researchers. The first step was to determine definitions of culture through an exploration of the need to maintain cultural values from a practical perspective while considering any theoretical gaps in = designing table specifications. In designing an instrument for assessing the internalization and actualization levels of junior high school students' positive cultural values, the researchers made the following guidelines. First, they examined the conceptual definition. Then, they made an operational definition. Third, the researchers considered the indicators of national cultural values as referred to in the included questionnaire.

Based on the conceptual definition, culture is defined by the dynamic, explicit, and implicit rules of a system that a group of people has created and used to ensure their survival. In this context, culture encompasses the 
attitudes, values, beliefs, norms, and behaviors that groups of concerned people share and pass down to other generations. Another definition of culture defines values as the soul and basis to all forms of culture. The order of life and community activities is a concrete reflection of their cultural values. In addition, the operational definition of culture in this proposed instrument are cultural values that will be measured in the process of internalization and actualization of students are behaviors that are following the goals and strategies of national development and lead to the realization of a distinctive civilization based on the philosophy and outlook of the developing Indonesian nation. The indicators of the national cultural values referred to in this questionnaire include seven components. The first component is achievement, or trying to get the best results and use the opportunities presented by the teacher as productively as possible. The second component is confidence which refers to having the ability to express an opinion out loud whether in front of a classroom or at a public event. Third, the component of creativity comprises the ability to find new solutions to existing problems. The fourth component, sincerity, refers to listening to teachers when they are explaining concepts, speaking respectfully to both teachers and friends, and not interrupting conversations. The fifth component, discipline, requires that students use their time properly, aim to be role models, and maintain an orderly and obedient presence at school. Sixth, the component of nationalism, encourages students to learn about national heroes and be proud to be a part of Indonesian society. The seventh component is for tolerance, which is to appreciate and respect opinions from their own and learn to respect each other under those differences. From those components, we constructed some indicators and then broke them down into some practical statements. Table 1 shows the indicator of national cultural values considered in the instruments. The seven cultural values were then developed based on their value's indicators. However, each cultural value has a different number of questions. In the first phase, the number of questions of the whole is 30 points with a five scale. For the scoring system, we adopted Linkert-in a five-rating scale with the following guideline. For favorable (positive) determinations: "Strongly Agree" has a score of 5, "Agree" has a score of 4, "Doubt" has a score of 3, "Disagree" has a score of 2, and "Strongly Disagree" has a score of one. For unfavorable (negative) determinations: "Strongly Disagree" has a score of 1, "Disagree" has a score of 2, "Doubt" has a score of 3 , "Agree" has a score of 4, and "Strongly Agree" has a score of 5. The maximum score is 120, and the minimum score is 30. For the descriptive consideration, we categorized them into three scores: Good (range of 80 to 120), Middle (range of 54 to 79), and Poor (range of less than 53).

Furthermore, we divided the cultural components into seven groups: 1) religious system and ceremonies, 2) system and society organization, 3) knowledge system, 4) language, 5) art, 6) employment system, and 7) technology. The elements were split into narrower sub-elements. Since the religious system and ceremonies are at the highest value level, seemingly, this component may be most difficult to affect toward the students' understanding. There are, however, some possibilities for change with religious equipment and technology. It is in line with the development of technology in the community. On the other hand, cultural elements, such as art, the employment system, and technology will be very easily affected. It depends on how strongly the religion or dogma is practiced by the community. Since culture is a set of practices, codes, and values (Richards \& Schmidt, 2011), it can be categorized into its group.

\subsection{The Notion of Cultural Values in Language Teaching}

Regarding education, there are many ways to bring cultural values into teaching and learning activities by integrating culture through teaching material and some learning activities. To preserve a positive culture, education has a dynamic role. However, an instrument is needed to assess how far students can understand cultural values taught in their classrooms. an appropriate instrument to assess positive culture in teaching will foster learners' wisdom and sensibility. As Rahyono (2009) states in his book, local wisdom is comprehensive, keen, and clever and is created based on people's experiences until those are possessed together. Since the local wisdom contained some precious value, it will be beneficial if teachers interactively teach them to the students. 
Table 1. The indicator of national cultural values is considered in the instruments.

\begin{tabular}{|c|c|c|c|c|c|}
\hline Num. & Cultural Values & Values Indicators & Number of Questions & Statements & Scale \\
\hline 1. & Achievements & $\begin{array}{l}\text { 1. Trying to get the best results. } \\
\text { 2. Using opportunities given by teachers as } \\
\text { much as possible. }\end{array}$ & $\begin{array}{l}5 \\
\text { Positive: } 3 \\
\text { Negative: } 2\end{array}$ & $\begin{array}{l}\text { I. I study hard to get results. } \\
\text { 2. I study before bedtime and for } 20 \text { minutes or less. } \\
\text { 3. I got a grade that my parents are happy with. } \\
\text { 4. I prepare a cheat sheet during school exams. } \\
\text { 5. I take all school assignments seriously. } \\
\end{array}$ & $1-5$ \\
\hline 2. & Confidence & $\begin{array}{l}\text { 1. Confidence in expressing opinions. } \\
\text { 2. Confidence in speaking in public. }\end{array}$ & $\begin{array}{l}3 \\
\text { Positive: } 2 \\
\text { Negative: } 1\end{array}$ & $\begin{array}{l}\text { 6. I actively ask questions in discussion groups. } \\
\text { 7. If there are positive things, I am not ashamed to discuss them. } \\
\text { 8. I feel inferior so I refuse when my teacher asks me to present. }\end{array}$ & $1-5$ \\
\hline 3. & Creativity & $\begin{array}{l}\text { 1. Be able to find new solutions to existing } \\
\text { problems. } \\
\text { 2. Listen attentively to the teacher and } \\
\text { speaking politely. } \\
\text { 3. Avoid interruptions during classroom time. }\end{array}$ & $\begin{array}{l}3 \\
\text { Positive: } 2 \\
\text { Negative: } 1\end{array}$ & $\begin{array}{l}\text { 9. I take time to read critically so I can solve a problem. } \\
\text { 10. When there is a problem, I do not try to solve it. } \\
\text { 11. Once a conflict arises amongst my classmates, I try to help to } \\
\text { resolve the issue fairly. }\end{array}$ & $1-5$ \\
\hline 4. & Respect & $\begin{array}{l}\text { 1. Listening to the teacher while they are } \\
\text { talking. } \\
\text { 2. Speaking politely to teachers and friends. } \\
\text { 3. Do not interrupt during the conversation. }\end{array}$ & $\begin{array}{l}5 \\
\text { Positive: } 2 \\
\text { Negative: } 3\end{array}$ & $\begin{array}{l}\text { 12. When a teacher explains the lesson, I listen carefully. } \\
\text { 13. During class, sometimes I sleep or talk with my classmate. } \\
\text { That is the solution. } \\
\text { 14. I interrupt and talk while the teacher is teaching. } \\
\text { 15. Before the class ends, I leave the room without permission } \\
\text { from the teacher. } \\
\text { 16. I speak rudely and loudly to my friends, so they respect me. }\end{array}$ & $1-5$ \\
\hline 5. & Discipline & $\begin{array}{l}\text { 1. Make the best use of time. } \\
\text { 2. Can be a role model. } \\
\text { 3. Maintain a school environment. } \\
\text { 4. } \quad \text { Orderly and obey the rules. }\end{array}$ & $\begin{array}{l}5 \\
\text { Positive: } 2 \\
\text { Negative: } 3\end{array}$ & $\begin{array}{l}\text { 17. I carry out all activities properly and regularly. } \\
\text { 18. I participate in activities and organizations at school. } \\
\text { 19. I use my cell phone in class. } \\
\text { 20. I throw garbage in the school desk drawer. } \\
\text { 21. Five minutes before class time, I was already in class and } \\
\text { ready to take lessons. }\end{array}$ & $1-5$ \\
\hline 6. & Nationalism & $\begin{array}{l}\text { 1. Learn about national heroes. } \\
\text { 2. Proud to be Indonesian society. }\end{array}$ & $\begin{array}{l} \\
\text { Positive: } 2 \\
\text { Negative: } 2\end{array}$ & $\begin{array}{l}\text { 22. I read books about the stories of heroes to learn. } \\
\text { 23. I prefer to be friends with students from abroad than } \\
\text { Indonesian students. } \\
\text { 24. I am grateful to be an Indonesian citizen. } \\
\text { 25. I change my citizenship status on social media. }\end{array}$ & $1-5$ \\
\hline 7. & Tolerance & $\begin{array}{l}\text { 1. Appreciate differences of opinion. } \\
\text { 2. Respect the differences in the cultural } \\
\text { values of other communities. }\end{array}$ & $\begin{array}{l}5 \\
\text { Positive: } 3 \\
\text { Negative: } 1\end{array}$ & $\begin{array}{l}\text { 26. I respect my friends who have different opinions. } \\
\text { 27. I avoid making friends whose different beliefs. } \\
\text { 28. I learn across cultures to increase knowledge on how to make } \\
\text { friends at the local, national, and international levels. } \\
\text { 29. Teaching cultural diversity as a value is not useful in life. } \\
\text { 30. Learning the cultural values of Western nations is useful for } \\
\text { minimizing misunderstanding in communicating with them } \\
\text { and opening up insights on cultural differences. }\end{array}$ & $1-5$ \\
\hline
\end{tabular}


In line with the previous arguments, the researchers believe that developing an instrument to assess the internalization and actualization of cultural values would be helpful. In addition, teaching with the help of culturebased lessons initiated by research and developed with a certain procedure would meet the learners' needs. Furthermore, students can help support other students to internalize and actualize positive values.

Having discussed the culture based on the theoretical perspective, this research attempts to develop an instrument to assess the internalization and actualization of cultural values through English teaching and learning activities. It is necessary to do because the teacher can control and observe the learners' understanding of cultural values in their daily life.

\subsection{The Interpretation of Exploratory Factor Analysis}

After the instrument had been completely designed, then expert judgments evaluated it based on some considerations. Then, the following step was testing the instrument on the students at junior high schools in English classes.

Students were tested on 25 final items. Five questions were eliminated because they were in the same category. From the measurement, it could be found that 25 items were appropriate to measure internalizing and actualizing of cultural values. They were validated both from the content and construct validity. To reveal the content validity, the questionnaires were developed based on the table of specifications, whereas to maintain the construct validity, they were discussed with experts with experience. Then, were tested in the final phase to find the empirical evidence. To figure out the empirical data, we analyzed the questionnaires using statistical analysis, particularly for factor analysis. We aimed to understand any kind of factors that supported the measurement of learners' affective domain. Having been analyzed, there were eleven factors stated in the first draft with 40 indicators of prepared instruments. However, after we had discussed it with the expert judgments, there were some points that we must omit because they have similarities with the other items. After we finalized the questionnaires, we then tested them on the students in four junior high schools. The IBM Statistical Package for Social Science (SPSS) Statistics Data Editor 20.0 for Windows, the KMO test, and Bartlett's Test were applied to analyze the questionnaires.

The use of the KMO test and Bartlett's Test was to make sure that all of the factors that had been prepared and designed in the questionnaires were representative. Later on, several weeks before the questionnaires were used in the tryout, the result of the KMO and Bartlett's Test had been acquired. The extraction of analytical factor analysis was presented in the following table.

Table 2. The result of KMO and bartlett's test.

\begin{tabular}{l|c|c}
\hline \multicolumn{2}{c|}{ Kaiser-Meyer-Olkin Measure of Sampling Adequacy } & $\mathbf{0 . 5 8 7}$ \\
\hline \multirow{3}{*}{ Bartlett's Test of Sphericity } & Approx. Chi-Square & 1464.240 \\
\cline { 2 - 3 } & Df & 435 \\
\cline { 2 - 3 } & Sig. & 0.000 \\
\hline
\end{tabular}

Having processed the data using the KMO Measure of Sampling Adequacy, the result revealed 0.587 with a significance of 0.000. Since the final result proceed by the KMO Measure of Sampling Adequacy reached more than $0,5(p>0,5)$, the researcher KMO Measure of Sampling Adequacy recommended the final score by omitting some components into six components. The entire statistical analysis mainly used the KMO test, and Bartlett's Test is enclosed in this paper.

\subsection{Result of Culture Values Questionnaire Validity}

Based on consideration from the statistical computation, the result of test validity and reliability of the research instruments are found to be valid and reliable. An item's validity was aimed at making sure the appropriateness and usefulness of the instruments, thus, the reliability, was aimed at determining the test's consistency and stability. 
Having made the statistical calculation, we found a valid and reliable result and used them to gain expected data. Then, we could generalize, as a whole, the result of the final data analysis of the research.

\subsection{Result of Culture Values Questionnaires Reliability}

We applied the Alpha Cronbach formula to determine the reliability of the instruments. It aimed at measuring the reliability of the questionnaires for items. The calculation used the IBM SPSS. The result of the reliability test was reliable because the percentage reached 0.871 . It was exactly higher than 0.7 . Based on the assumption of the Alpha Cronbach coefficient, it ought to be higher than 0.7. The data calculation is in Table 2.

Table 3. Reliability Statistics Analysis of Cronbach's Alpha.

\begin{tabular}{c|c}
\hline Cronbach's Alpha & N of Items \\
\hline 0.871 & 30 \\
\hline
\end{tabular}

From Table 3, we can see the result of the item's reliability from the statistics of Cronbach's Alpha. As the score was .871 , it means that the instruments were considered reliable as the score is more than 0.7 . It is understood, therefore, that the instruments can be used to measure students' cultural values. This decision is based on Eisingerich and Rubera (2010) that the value of the minimum reliability level of Cronbach's Alpha is 0.70. From the smallest standard score, or the limit score. However, the 30 items, which measure cultural values actualized by the students, can be considered reliable as the score is more than 0.70. The result of measurement has supported this argument as the result of item internal consistency is more than the limit score.

Based on the consideration from the statistical computation, the result of test validity and reliability of the research instruments deserved to be valid and reliable. An item's validity was aimed at making sure the appropriateness and usefulness of the instruments, thus, reliability, was aimed at finding out the test's consistency and stability. Having found their statistical calculation, they had been proven valid and reliable. Then, they could gain the expected data, and the result of the final data analysis of the research could be generalized as a whole.

\subsection{The Result of Instruments Implementation}

To know the quality of the instrument, we tested the questionnaires on the learners to know their level of internalization and actualization of the cultural values. The questionnaire utilized in that objective consisted of 25 items with five scales. The questionnaire consisted of seven factors. They were: (1) deserving the value of achievement, (2) self-confidence, (3) creativity, (4) respect, (5) discipline, (6) nationalism, and (7) tolerance.

The measurement instruments used the Likert scale with the option of favorable as the positive response and unfavorable as the negative response. The description of the response comprised: 4. indicated constantly, 3. indicated frequently, 2. indicated infrequently, and 1. indicated never. The description of each category encompassed the maximum score that was around 100 until 25 as the minimum score. The students would be judged to have a very good understanding and manner of acting if their score reached 78 until 10o. If the student had a score between 63 and 77, they had a good understanding and manner of acting. When the score was less than 62 , this indicated that the student needed intensive guidance. The following data showed the summary of statistical descriptive which is categorized into three: Very Good, Good, and Fair.

Table 4. Statistical descriptive of cultural values internalization and actualization.

\begin{tabular}{l|c|c|c}
\hline Criteria & Descriptions & Frequency (Students) & Percent \\
\hline A & Very Good & 32 & $47.1 \%$ \\
\hline B & Good & 36 & $52.9 \%$ \\
\hline C & Fair & 0 & 0 \\
\hline Total & & 68 & $100 \%$ \\
\hline
\end{tabular}


The statistical descriptions guide us to understand a student's level of cultural values. Based on the accumulation, nearly half of the English-learning students in this study had very good actualization and actualization of cultural values. In addition, students with a good level of internalization and actualization made up $52.0 \%$ or half of the total students in the study.

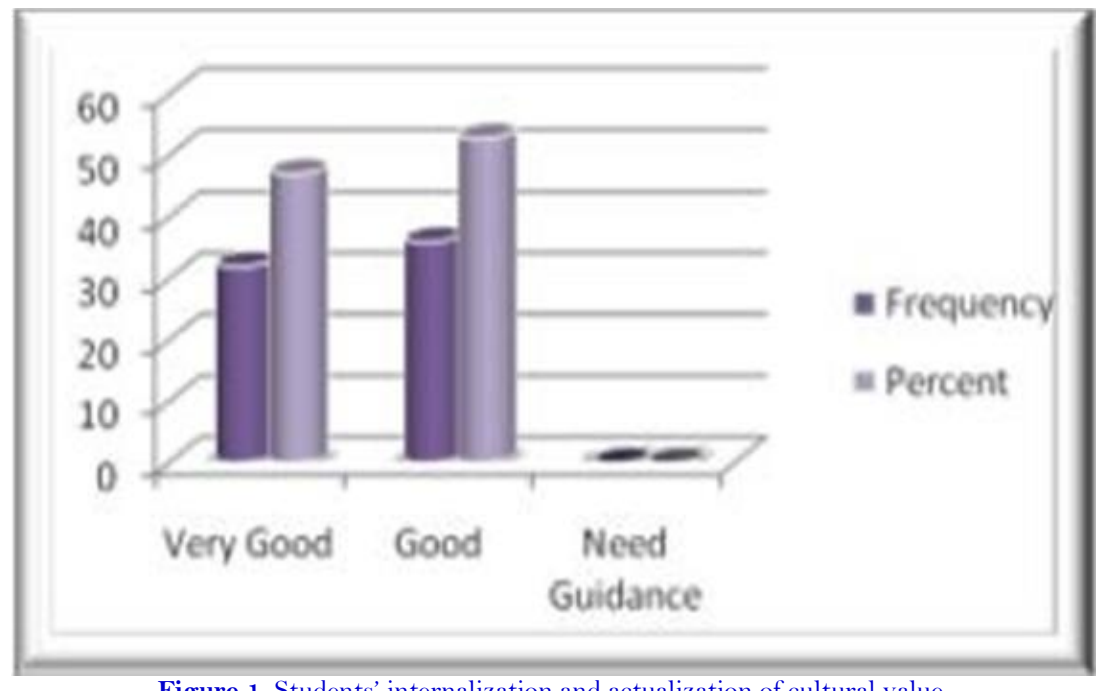

Figure 1. Students' internalization and actualization of cultural value.

In general, the students' cultural values understanding including their internalization and actualization can be represented in Figure 1. To get a better understanding of the information that has been given regarding the integration of culture in English language teaching in junior high schools, the visualization presented in Figure 1 shows the results of this research.

\section{CONCLUSION}

This study aimed to develop an instrument to assess learners' internalization and actualization of cultural values through English for foreign language learning. The five phases of instructional design proposed by Cennamo and Kalk (2019) guided this research and development. The five phases of instructional design included (1) defining key terms and exploring the need to develop an instrument from a practical perspective while considering any theoretical gaps; (2) creating the instrument grid design and table of specifications for the design; (3) developing and modeling the instrument; (4) refining the instrument using input from forum group discussions and expostulating with expert judgments; and (5) presenting the product and testing it to the learners.

The technique to analyze the data used exploratory factor analysis (EFA). The number of samples in this research determined the factor loading within the EFA. The Kaiser-Meyer-Olkin (KMO) was used as the consideration of the sufficiency of the data with a level more than 0,05 (KMO>0.05). After analyzing the data, the result revealed 0,587 with a significance of 0.000 . The result of the study showed that for assessing internalization and actualization of cultural values, there are 25 items with seven factors: deserving the value of achievement, selfconfidence, creativity, respect, discipline, nationalism, and tolerance.

Based on the research and development done to assess the level of internalization and actualization of positive cultural values for learners, the results of this research can be productively and successfully utilized to help foreign language learners. By using this instrument, teachers will be able to map the learners' level of progress, especially related to their domain of affection. However, several things need to be considered regarding the results of this first study, including the context or background of the learner as well as the learning material used will influence the questionnaire used. This is because the questionnaire is only intended for teachers to assess the attitude of students in English classes. 
Funding: This study received no specific financial support.

Competing Interests: The authors declare that they have no competing interests.

Authors' Contributions: All authors contributed equally to the conception and design of the study.

\section{REFERENCES}

Berlin, D. F. (1992). Validation of an instrument to measure understanding of pattern by elementary school children. Perceptual And Motor Skills, 74, 1225.Available at: Https://Doi.Org/10.2466/Pms.74.4.1225-1226.

Cennamo, K., \& Kalk, D. (2019). Real world instructional design: An iterative approach to designing learning experiences. Oxfordshire: Routledge.

Chaer, A., \& Agustina, L. (2010). Sociolinguistics: An early introduction. Jakarta: Rineka Cipta.

Díaz-Cabrera, D., Hernández-Fernaud, E., \& Isla-Díaz, R. (2007). An evaluation of a new instrument to measure organisational safety culture values and practices. Accident Analysis \& Prevention, 39, 1202-1211.Available at: Https://Doi.Org/10.1016/J.Aap.2007.03.005.

Eisingerich, A. B., \& Rubera, G. (2010). Drivers of brand commitment: A cross-national investigation. Journal of International Marketing, 18(2), 64-79.Available at: https://doi.org/10.1509/jimk.18.2.64.

Gabryś-Barker, D. (2016). Caring and sharing in the foreign language class: on a positive classroom climate. In Positive psychology perspectives on foreign language learning and teaching (pp. 155-174). Cham: Springer.

Gay, G. (2010). Culturally responsive teaching: Theory, research, and practice. New York: Teachers College Press.

Gregersen, T. (2016). The positive broadening power of a focus on well-being in the language classroom. In Positive psychology perspectives on foreign language learning and teaching (pp. 59-73). Cham: Springer.

Harpham, G. G. (2017). It just must be true: Tomasello on cognition and morality. Evolutionary Studies in Imaginative Culture, 1(1), 193-202.Available at: https://Doi.Org/10.26613/Esic.1.1.26.

Jensen, L. A. (2015). Theorizing and researching moral development in a global world. In L. A. Jensen (Ed.), Moral development in a global world: Research from a cultural-developmental perspective (pp. 1-19): Cambridge University Press.

Khan, M., Waheed, M., Chengwen, H., Butt, T. M., \& Ahmad, J. (2018). Development and perspectives of English, as a language of instruction and learning in Chinese educational system. Asian Journal of Contemporary Education, 3(1), 2835.Available at: https://doi.org/10.18488/journal.137.2019.31.28.35.

Kiss, C., \& Nikolov, M. (2005). Developing, piloting, and validating an instrument to measure young learners' aptitude. Language Learning, 55(1), 99-150.Available at: https://doi.org/10.1111/j.0023-8333.2005.00291.x.

Koentjaraningrat. (1997). Methods - community research methods. Jakarta: PT. Gramedia Pustaka Utama.

Kroeber, A. L., \& Kluckhohn, C. (1952). Culture; a critical review of concepts and definitions. Cambridge: The Museum.

Kumaravadivelu, B. (2003). Beyond method. London: Yale University Press.

Kurth, A., \& Narvaez, D. (2018). The evolved developmental niche and children's developing morality. The Child's Curriculum: Working with the Natural Values of Young Children, 105-125.Available at: https://doi.org/10.1093/oso/9780198747109.003.0006.

MacIntyre, P. D., \& Mercer, S. (2014). Introducing positive psychology to SLA. Studies in Second Language Learning and Teaching, 4(2), 153-172.Available at: https://doi.org/10.14746/ssllt.2014.4.2.2.

Martinez, I., \& Garcia, J. F. (2008). Internalization of values and self-esteem among Brazilian teenagers from authoritative, indulgent, authoritarian, and neglectful homes. Adolescence-San Diego, 43(169), 13-29.

Park, N., \& Peterson, C. (2006). Moral competence and character strengths among adolescents: The development and validation of the values in action inventory of strengths for youth. Journal of Adolescence, 29(6), 891-909.Available at: https://doi.org/10.1016/j.adolescence.2006.04.011.

Piasecka, L. (2016). Activating character strengths through poetic encounters in a foreign language—a case study. In Positive psychology perspectives on foreign language learning and teaching (pp. 75-92). Cham: Springer.

Rahyono, F. (2009). Cultural wisdom in the word. Jakarta: Wedatama Widyasastra.

Richards, J. C., \& Schmidt, R. (2011). Longman dictionary of language teaching and applied linguistics. Oxfordshire: Routledge. 
Saifer, S., Edwards, K., Ellis, D., Ko, L., \& Stuczynski, A. (2012). Culturally responsive standards-based teaching: Classroom to community and back. Thousand Oaks, CA: Corwin Press.

Staines, D., Formosa, P., \& Ryan, M. (2019). Morality play: A model for developing games of moral expertise. Games and Culture, 14(4), 410-429.Available at: https://doi.org/10.1177/1555412017729596.

Staub, E. (1979). Summary and conclusions: The development of positive social behavior and morality. Positive Social Behavior and Morality, 25 1-276.Available at: Https://Doi.Org/10.1016/B978-0-12-663 102-9.50014-6.

Talamini, F., Grassi, M., Toffalini, E., Santoni, R., \& Carretti, B. (2018). Learning a second language: Can music aptitude or music training have a role? Learning and Individual Differences, 64, 1-7.Available at: https://doi.org/10.1016/j.lindif.2018.04.003.

Vauclair, C. (2009). Measuring cultural values at the individual-level: Considering morality. Cross-Cultural Value Research, RamMackenzie Management Magazine, 10(3), 60-83.Available at: https://doi.org/10.1590/s1678-69712009000300005.

Zakarneh, B. I., Alsalhi, N. R., Talab, A. R. A. B., Mansour, H. M., \& Mahmoud, M. M. J. (2021). Social interactions as a barrier to second language learning: A sociocultural perspective. International Journal of English Language and Literature Studies, 1O(2), 145-157.Available at: https://doi.org/10.18488/journal.23.2021.102.145.157.

Views and opinions expressed in this article are the views and opinions of the author(s), Humanities and Social Sciences Letters shall not be responsible or answerable for any loss, damage or liability etc. caused in relation to/arising out of the use of the content. 